\title{
Estudo dos recursos estilísticos presentes no prólogo (prefácio) do livro Úrsula, obra literária de Maria Firmina dos Reis
}

Tânia Regina Santos Fernandes ${ }^{\mathrm{i}}$

\section{RESUMO}

Este estudo tem como objetivo apresentar uma reflexão sobre o estilo da linguagem verbal empregada na elaboração do texto que apresenta a obra ficcional Úrsula, de Maria Firmina dos Reis, uma análise que partirá da observação de vocábulos utilizados para configurar a ornamentação dos recursos estilísticos evidenciados pela linguagem figurada utilizada pela escritora para apresentar a própria narrativa ficcional. Para isso, serão considerados estudos sobre o uso da expressividade linguística já desenvolvidos por Pierre Guiraud, M. R. Lapa, Marcel Cressot e Nilce Sant'Anna, visando uma aplicação para atividades de estímulo à leitura em salas de aula dos anos finais do Ensino Fundamental.

Palavras-chave: Vocábulos; Recursos; Narrativa; Expressividade; Leitura.

\section{RÉSUMÉ}

L'objectif de ce travail est de promouvoir la réflexion à propos du style de langage verbal utilisé dans l'élaboration du texte de présentation de l'œuvre fictive Úrsula, de Maria Firmina dos Reis, partant de l'observation des mots employés pour construire l'ornementation des ressources stylistiques mises en évidence à travers le langage métaphorique utilisé par l'écrivaine dans la présentation de son propre récit fictif. Pour ce faire, il sera pris en compte les études sur l'expressivité linguistique développées par Pierre Guiraud, M. R. Lapa, Marcel Cressot et Nilce Sant'Anna, visant à l'application d'activités qui encouragent la lecture dans les salles de classe au collège.

Les mots-clés: Mots lexicaux; Ressources; Récit; Expressivité; lecture.

\footnotetext{
${ }^{\text {i }}$ Formada em Letras (Bacharelado e Licenciatura) pela UFRJ, mestranda do Programa de Pós-graduação em Letras - UERJ - Área: Estudos de língua - Especialidade em Língua Portuguesa. ORCID: https://orcid.org/0000-0002-6846-7980 | taniarfernandes12@gmail.com
} 


\section{INTRODUÇÃO}

Ao examinar minunciosamente o leiaute de um livro, é possível observar a disposição de vários elementos que compõem esse material. Impresso ou não, esse objeto de produção escrita muitas vezes expõe um certo padrão de projeto gráfico que, ao longo da história, foi sendo construído para apresentar informações relacionadas ao seu próprio conteúdo.

Os elementos que compõem a diagramação de um livro, de certa maneira, também podem remeter a uma determinada funcionalidade para efeito da apresentação final do produto elaborado, pois há alguns componentes editoriais que, não apenas, configuram forma, mas também compõem sua estrutura final, como é o caso, por exemplo, de uma obra literária, na qual, por vezes, há, em sua diagramação, um pequeno texto que cumpre a função de apresentar essa obra a fim de colaborar com a sua divulgação e cativar no leitor um certo interesse pela narrativa constituída no livro.

Embora haja quem julgue um livro apenas pela sua capa, não é muito difícil encontrar aquelas pessoas que vão um pouco mais além e buscam compreender todas as partes que compõem um livro antes mesmo de se aventurar na leitura.

Como elementos textuais, não há como negar que, entre os que compõem a diagramação de um livro, há aqueles que, de fato, trazem informações capazes de expressar sua finalidade, seu propósito e conseguem cativar interesse para a recepção do livro. Como é o caso do prefácio, um componente textual que vem sendo consolidado ao longo do tempo e já cumpre uma função dentro do projeto de diagramação de quaisquer obras literárias, não só por veicular informações que, de certa forma, resumem o assunto temático do livro como para despertar curiosidades prévias que sirvam para incentivar uma determinada prática leitora, a fim de torná-la um meio satisfatório para o exercício da chamada leitura de fruição.

Diante disso, essas observações sobre o leiaute de uma obra literária podem remeter à noção de paratextos ${ }^{1}$, elementos periféricos ao texto e que, de acordo com Genette (2009), podem ser divididos em dois grupos: os epitextos, elementos exteriores ao texto, e os peritextos, elementos situados em torno do texto, sendo estes últimos componentes textuais ou verbo-visuais, elementos pertencentes à própria confecção do livro. 
Como componentes internos, é possível identificar o título da obra, as ilustrações, a dedicatória, as epígrafes, os posfácios, os prefácios, entre outros que se apresentem em uma forma textualizada cuja significação, de certa maneira, cumpra uma finalidade no conjunto da composição.

Como exemplo de um componente paratextual conhecido como peritexto, o prefácio é um dos que há muito tempo foi sendo consolidado no leiaute de um projeto gráfico com a função de apresentar o texto escrito, ou seja, normalmente remete ao assunto temático do livro. Isso é o que pode ser verificado a partir do texto que antecede o romance Úrsula (1859), de Maria Firmina dos Reis. Um texto que, apesar de não estar definido ou nomeado como um prefácio, nem mesmo nas edições mais atuais do livro da autora, sua composicionalidade surge como resultado de uma configuração cujo conteúdo significativo cumpre a função de apresentar a obra romanesca e ficcional da autora.

Se, por um lado, no que se refere à elaboração e significação dos itens linguísticos de uma obra ficcional já é esperada a utilização de uma linguagem repleta de artifícios imagéticos para a composição romanesca de sua narrativa, realizada por meio de tropos ou figuras de linguagem - elementos característicos do estilo da linguagem literária, por outro lado, o que se pode esperar de um texto prefacial que compõe essa mesma obra?

Normalmente, não há regra definidora do estilo a ser empregado em uma composição que cumpra a função de prefaciar qualquer livro, nem mesmo uma narrativa ficcional. No entanto, parece que sua consolidação como uma produção cuja finalidade é a de apresentar o livro em si, ocorre mesmo sem regras pré-definidas. É essa especificidade singular do modo de apresentar uma obra literária que será verificada neste trabalho, a partir da leitura de um texto - objeto de análise neste estudo - escrito pela própria autora ${ }^{2}$ do romance narrativo, tendo como propósito verificar traços do seu estilo narrativo que se assemelhem aos recursos expressivos da linguagem literária conhecidos como tropos.

Para Guiraud (1970, p. 31), essas "figuras constituem a base de uma teoria do ornamento", uma maneira diferenciada de praticar a linguagem que são conhecidas por figuras de palavra, as mesmas que, na visão de Cressot (1947, p. 64), aparecem como "processos que permitem obter uma alteração no sentido das palavras". Nesse sentido, 
os exemplos aplicados servem para ilustrar como a autora utilizou-se do mesmo ornamento da linguagem figurada presente no texto narrativo da obra para apresentá-la, o que será feito, destacando alguns dos recursos expressivos utilizados mediante as escolhas lexicais e estruturais, com as quais é constituído o sentido conotativo no texto prefacial, e ao mesmo tempo vão atribuindo-lhe uma certa finalidade comunicativa.

É possível notar nesse artifício de construção da linguagem presente no texto prefacial que há a predominância de duas das três modalidades da linguagem - entre a intelectiva, a afetiva e a estética, conforme colocadas em Azeredo (2018).

Tendo em vista o modo como foi elaborado o texto prefacial, ou seja, uma arquitetura composicional repleta de expressões ligadas ao artifício estético literário e que, ao mesmo tempo, cumpre uma finalidade comunicativa, a de apresentar a narrativa, é possível perceber que em alguns contextos de produção e uso da linguagem verbal não há delimitação exata entre as fronteiras da linguagem intelectiva, a linguagem afetiva e a linguagem estética.

Com o propósito de alcançar, no entanto, algum parâmetro que direcione o entendimento sobre o que está no nível da interpretação e o que pode ser inferido apenas pelo método da compreensão, a intenção é “estabelecer alguns princípios básicos capazes de caracterizar a predominância de uma delas" (AZEREDO, 2018, p. 520).

A partir desse raciocínio, para o processo de desenvolvimento deste trabalho, verifica-se o estilo da linguagem predominante no texto, que será comentada a partir da perspectiva de estudos sobre o assunto, o que será feito mediante destaque dos recursos estilísticos elaborados, os mesmos cujos efeitos expressivos compuseram a linguagem metafórica e, ao mesmo tempo, cumpriram a finalidade comunicativa de apresentar o livro que, mesmo em uma linguagem figurada, não perdeu sua propriedade de texto prefacial da narrativa composta.

\section{REFERENCIAÇÕES TEÓRICAS SOBRE O ESTILO DA LINGUAGEM PRESENTE NO TEXTO PREFACIAL ANALISADO}

Os estudos sobre os efeitos da escolha lexical a partir de determinados contextos de produção escrita, bem como os modos de estruturação desses termos da língua para a construção do sentido intencionado por quem escreve ou mesmo a construção do 
sentido percebido por quem lê parecem não dar conta de tantas possibilidades de uso e emprego da linguagem verbal, talvez por isso pareçam ser intermináveis, principalmente devido ao fato de ter sido há muito tempo constatado que a língua não é estática, ela se transforma pelo uso; portanto, além de ser variável no tempo e no espaço, a língua por ser utilizada em diversos contextos de usos sociais de linguagem verbalizada, ela é continuamente organizada e (re)estruturada para refletir as suas várias finalidades, mostrando-se também dinâmica no que se refere aos contextos de produção.

É essa dinamicidade da linguagem verbal que vai dando rumo a muitos estudos sobre a língua tanto no que se refere à oralidade quanto à escrita, inclusive para a verificação do modo como ela é empregada. Entretanto, esse dinamismo não ocorre sem os contextos reais de uso da linguagem verbalizada. Nesse sentido, o indivíduo tanto pode ser "influenciado pela sensibilidade linguística do grupo e da época a que pertence" (CRESSOT, 1947, p. 16) quanto pode influenciar aqueles que o cercam. É, pois, essa sensibilidade linguística um dos pilares da estilística - ciência do estilo - que, na prática, pode ser um mecanismo da área de estudos da língua para que essa sensibilidade enunciada possa ser verificada por intermédio da "escolha do vocabulário, do material gramatical, da ordem das palavras, do movimento e da música da frase" (Ibidem, p. 16). Além disso, soma-se a essa expressividade linguística uma certa intenção de quem enuncia, conhecida como o elemento motivador da expressão linguística, ou seja, aquela intenção discursiva que auxilia na escolha de cada elemento linguístico para a estruturação do pensamento.

A partir dessas colocações, e considerando a comunicabilidade que pode ser inferida do texto prefacial do livro Úrsula, é possível verificar que há uma informação sendo vinculada. E a maneira como isso ocorre parece demonstrar o intuito de fazê-la conotativamente como uma espécie de cartão de visita que antecede à leitura do romance.

A informação do texto prefacial não é feita de modo objetivo, verifica-se que há uma pretensão estética em sua elaboração, portanto, uma "intenção, um desejo de impressionar o destinatário" (Ibidem, p. 13) por intermédio de uma linguagem figurada que precisa ser interpretada de acordo com os recursos expressivos e os elementos linguísticos apresentados no próprio texto para, então, poder “assegurar o máximo de 
eficácia ao seu ato de comunicação" (CRESSOT, 1947, p. 14) inferido daquele contexto.

Para prosseguir com as observações propostas neste estudo, é preciso que o texto para a análise seja previamente conhecido. Por esse motivo, segue abaixo transcrição do texto atribuído à Maria Firmina do Reis.

Mesquinho e humilde livro é este que vos apresento, leitor. Sei que passará entre o indiferentismo glacial de uns e o riso mofador de outros, e ainda assim o dou a lume.

Não é a vaidade de adquirir nome que me cega, nem o amor-próprio de autor. Sei que pouco vale este romance, porque escrito por uma mulher, e mulher brasileira, de educação acanhada e sem o trato e a conversação dos homens ilustrados, que aconselham, que discutem e que corrigem, com uma instrução misérrima, apenas conhecendo a língua de seus pais, e pouco lida, o seu cabedal intelectual é quase nulo.

Então por que o publicas? perguntará o leitor.

Como uma tentativa, e mais ainda, por este amor materno, que não tem limites, que tudo desculpa - os defeitos, os achaques, as deformidades do filho - e gosta de enfeitá-lo e aparecer com ele em toda parte, mostrá-lo a todos os conhecidos e vê-lo mimado e acariciado.

O nosso romance, gerou-o a imaginação, e não o soube colorir, nem aformosentar. Pobre avezinha silvestre, anda terra a terra, e nem olha para as planuras onde gira a águia.

Mas ainda assim, não o abandoneis na sua humildade e obscuridade, senão morrerá à míngua, sentido e magoado, só afagado pelo carinho materno.

Ele semelha à donzela, que não é formosa; porque a natureza negou-lhe as graças feminis, e que por isso não pode encontrar uma afeição pura, que corresponda ao afeto da sua alma; mas que com o pranto de uma dor sincera e viva, que lhe vem dos seios da alma, onde arde em chamas a mais intensa e abrasadora paixão, e que embalde quer recolher para a corrução (sic), move ao interesse aquele que a desdenhou e o obriga ao menos a olhá-la com bondade.

Deixai, pois, que a minha ÚRSULA, tímida e acanhada, sem dotes da natureza, nem enfeites e louçanias de arte, caminhe entre vós.

Não a desprezeis, antes amparai-a nos seus incertos e titubeantes passos para assim dar alento à autora de seus dias, que talvez com essa proteção cultive mais o seu engenho, e venha a produzir coisa melhor, ou quando menos, sirva esse bom acolhimento de incentivo para outras, que com imaginação mais brilhante, com educação mais acurada, com instrução mais vasta e liberal, tenham mais timidez do que nós. (REIS, 2018, p. 47-48)

Tanto os aspectos linguísticos quanto os recursos expressivos, por cumprirem uma finalidade na composição do texto, demonstram ser elementos passíveis de compreensão e, além disso, ainda se constituem como um fato estilístico, por este reunir características "tanto de ordem linguística, como psicológica e social" (CRESSOT, 1947, p. 13) que podem, a partir do texto, ser verificáveis.

Um dos elementos que constitui a transferência de sentidos ou tropos muito evidenciada no texto é a metáfora, que, significativa e morfologicamente, "pode apresentar a forma de uma associação de dois objetos, sendo o objeto evocado, 
frequentemente utilizado como complemento determinativo do objeto-referência" (CRESSOT, 1947, p. 66).

Nesse sentido, a análise parte do emprego metafórico do vocábulo úrsula, destacado no penúltimo parágrafo do texto, conforme é possível perceber a seguir: “deixai, pois, que a minha ÚRSULA, tímida e acanhada, sem dotes na natureza, nem enfeites e louçanias de arte, caminhe entre vós" (REIS, 2018, p. 48) e, cujo efeito causado pela significação metafórica constitui, sob o ponto de vista geral, o sentido figurado no texto.

Diante desse exemplo sobre o uso metafórico, contextualmente é possível perceber que há

o emprego de um significante com um significado secundário ou a
aproximação de dois ou mais significantes, estando, nos dois casos, os
significados associados por semelhança, contiguidade, inclusão. A metáfora
resulta de uma busca, da qual participam a sensibilidade e a imaginação,
controladas pelo espírito crítico do poeta. Ela faz o jogo complexo do
significante e do significado; pode ser traduzida, parafraseada, pois é um
desvio em relação à linguagem comum, transferência ou mudança de sentido.
Transmite uma mensagem complexa semanticamente polivalente.
(MARTINS, 2012, p. 125-126)

É importante ressaltar que o fato do vocábulo úrsula aparecer grafado em caixa alta no texto que antecede ao romance narrativo em prosa, ou seja, com todas as letras em maiúsculas em um contexto discursivo específico - no interior da estruturação fraseológica que forma o período enunciado no parágrafo - já causa uma certa curiosidade por parte de quem esteja lendo o texto. Normalmente, esse é um tipo de expressividade gráfica um tanto incomum nesse contexto de elaboração textual (uma única palavra com todas as letras em maiúsculas no interior de um enunciado sem motivo aparente) que pode causar estranheza.

Quando esse recurso ortográfico eventualmente ocorre, pode estar relacionado ao que Martins destaca como "elementos emotivos". Para a autora, a tonalidade afetiva de uma palavra pode ser inerente ao próprio significado ou pode resultar de um emprego particular, sendo perceptível no enunciado em razão do contexto, ou pela entoação (enunciado oral), ou por algum recurso gráfico, como aspas, grifo, maiúsculas/minúsculas, tipos de impressão, e outros (enunciado escrito). (MARTINS, 2012, p. 106) 
Diante dessa colocação, esse artifício gráfico apresenta-se como um traço de ornamentação da linguagem cujo emprego serve para sinalizar um recurso estilístico com o provável intuito de chamar a atenção da pessoa que lê o texto. Nesse sentido, esse tipo de artifício estilístico presente na composição pode, inclusive, cumprir uma função discursiva para a elaboração de uma significação que tenha a finalidade de sinalizar para o próprio conteúdo narrado no livro, e, com isso, justificar o texto como uma apresentação indicativa da obra, ou seja, um prefácio.

Primeiramente, para tentar detalhar esse recurso estilístico, é preciso atentar para a significação literal do termo em questão. De acordo com o dicionário online de nomes próprios Infopédia (Antroponímia), o termo úrsula é "diminutivo do latim ursa, com o mesmo significado em português. O nome é bastante comum desde o século XII", o que sugere que esse termo pode ser empregado como nome próprio. Diante disso, uma vez que essa possibilidade de significação e uso do termo tenha sido constatada, ela passa a ser o ponto de partida para tentar alcançar o sentido elaborado no texto analisado.

Conotativa e referencialmente, no texto, o termo úrsula ora se assemelha "à donzela, que não é formosa; porque a natureza negou-lhe as graças feminis", ora é comparado e tido como fruto de uma "pobre avezinha silvestre", a imaginação; ou esse termo pode até mesmo ser compreendido pela ideia vinculada no enunciado apresentado já como primeiro período do texto prefacial, conforme destacado a seguir: "mesquinho e humilde livro é este que vos apresento, leitor".

Conforme pode ser observado, essas construções estão repletas do uso de adjetivos que, de acordo com Rodrigues Lapa (1982) também podem designar um certo valor afetivo pelo traço de intensidade que eles imprimem na elaboração do sentido da estruturação sintática.

Como primeiro exemplo, na primeira construção, destaca-se 'graças feminis'. Nesse caso, o vocábulo graças aparece como um substantivo, sendo qualificado pelo adjetivo feminis. Este último é um termo que, por estar posposto ao substantivo, conserva o sentido verdadeiro do adjetivo feminil, pois, nessa posição, "tende a conservar o valor próprio, objetivo, intelectual" (LAPA, 1982, p. 105). Além disso, esse é um termo que pode ser categorizado, conforme colocado pelo autor, como adjetivo literário por ter origem no termo latino feminale. Evidentemente, para os eventos discursivos da época atual, esse é um termo pouco usual, e sua significação pode ser 
facilmente expressada por termos mais correntes e atuais da língua, como feminina/femininas.

Pelo segundo exemplo, na construção “pobre avezinha silvestre”, é possível, primeiro, identificar o termo avezinha como substantivo cuja composição morfológica apresenta-se complementada por afixo; nesse caso, pelo uso do sufixo -inha, uma marca do diminutivo na língua. Esse é um recurso estilístico que, de acordo com Rodrigues Lapa, pode sugerir uma gradação. Já o termo lexical pobre, um adjetivo anteposto ao substantivo "tende a embrandecer-se, adquirindo matização afetiva" (LAPA, 1982, p. 105). Para o autor, significa que "esta variabilidade na colocação do adjetivo é própria de pessoas sentimentais e sonhadoras. O poeta que vive mais na esfera do sentimento, tem tendência para pôr o adjetivo antes do substantivo" (Ibidem, p. 105). A partir desse exemplo, ainda é possível destacar o adjetivo silvestre posposto ao substantivo avezinha. De acordo com a lógica de Rodrigues Lapa, nessa posição o termo define e qualifica o substantivo com o qual se articula de maneira intelectiva. Sendo assim, com esses exemplos, é possível constatar pelo uso da linguagem verbal contextualizada que a regra de colocação e uso do adjetivo na língua portuguesa não é rígida; pelo contrário, é flexível.

Finalmente, pelo último exemplo destacado do texto, na construção "mesquinho e humilde livro é este que vos apresento, leitor", também aparecem dois termos cuja função nesse contexto enunciativo ajuda a categorizá-los como sendo pertencentes ao grupo dos adjetivos. Todavia, eles também carregam traços para a construção de sentido que remetem a algumas observações já apresentadas com os exemplos anteriores.

Em relação ao substantivo livro, no que se refere à anteposição dos adjetivos mesquinho e humilde, o uso desses termos, conforme mencionado anteriormente, também implicaria um traço de afetividade.

Em relação a esse terceiro e último exemplo, no entanto, é preciso considerar não somente a posição dos adjetivos em relação ao substantivo, como também é importante enfatizar sobre o plano de significação do próprio lexema, principalmente quanto ao vocábulo mesquinho, pois, embora apresente em sua estruturação morfológica a segmentação silábica -inho, este termo não se constitui semântica e morfologicamente por um sufixo marcador do diminutivo da língua. Nesse sentido, é importante remeter às colocações de Nilce Sant'Anna Martins (2012) quando, ao 
abordar sobre as tonalidades emotivas das palavras, faz algumas ponderações sobre aquelas que transmitem um significado afetivo, aquelas que exprimem algum tipo de julgamento, aquelas de cunho avaliativo e, ainda, sobre aquelas palavras da língua que servem para evocar uma determinada significação. Sobre as palavras de significado afetivo a autora declara que elas

\begin{abstract}
são aquelas cujo lexema exprime emoção, sentimento, um estado psíquico. O lexema pode receber vogal temática, desinência ou afixo que o atualize como substantivo, adjetivo, verbo ou advérbio, podendo assim haver cognatos emotivos das várias classes de palavras lexicais [...] Através do adjetivo o falante caracteriza emocionalmente o ser de que fala; através do substantivo abstrato destaca o sentimento, a qualidade, o estado, apresentando-os com mais realce, menos presos ao ser. (MARTINS, 2012, p. 106)
\end{abstract}

Diante disso, para compreender melhor o significado afetivo dos termos

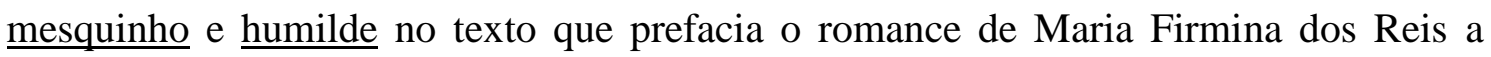
partir da colocação de Nilce Sant'Anna, é preciso que haja uma contextualização sobre a época em que esse texto foi escrito. Resumidamente, à época da produção do livro, em 1859, o cenário sociocultural era pouco favorável para a condição cidadã de atividade no âmbito de expressão literária da mulher descendente de escravos. Era uma cultura de aversão à condição sociocultural feminina que pode ser inferida do próprio texto, em seu segundo parágrafo destacado abaixo:

\footnotetext{
Não é a vaidade de adquirir nome que me cega, nem o amor próprio de autor. Sei que pouco vale este romance, porque escrito por uma mulher, e mulher brasileira, de educação acanhada e sem o trato e a conversação dos homens ilustrados, que aconselham, que discutem e que corrigem, com uma instrução misérrima, apenas conhecendo a língua de seus pais, e pouco lida, o seu cabedal intelectual é quase nulo. (REIS, 2018, p. 47)
}

Se for considerado que, pela compreensão do sentido geral alcançado a partir da leitura da composição é possível atribuir ao texto que antecede os capítulos a função para apresentar o livro, muito provavelmente também é possível, a partir dessa mesma compreensão, inferir a elaboração de relações metafóricas entre o livro e a personagem protagonista da narrativa. Além disso, compreender como a autora, ao comparar, no texto prefacial, sua obra literária a uma filha, não deixa de expressar a percepção sobre a condição de si mesma, ao equiparar-se àquela que "com uma instrução misérrima, apenas conhecendo a língua de seus pais, e pouco lida” (REIS, 2018, p. 47) estaria em 
desvantagem em relação ao que ela expressa como sendo "homens ilustrados, que aconselham, que discutem e que corrigem” (REIS, 2018, p. 47), uma comparação que, discursivamente remete à condição do papel social da mulher na referida época de publicação do livro.

Diante dessas observações, quanto aos termos lexicais mesquinho e humilde, é possível perceber que há um traço afetivo sendo expressado pelo uso desses itens quando compõem o enunciado "mesquinho e humilde livro é este que vos apresento, leitor” (REIS, 2018, p. 47), logo no início do texto. Entretanto, talvez esse enunciado seja o exemplo que melhor expressa a finalidade do texto prefacial que é a de tornar o romance narrativo conhecido, pois, em uma correlação com o sintagma nominal "mesquinho e humilde livro", o pronome demonstrativo este aparece como elemento anafórico, recuperando no próprio enunciado a significação do termo livro e, por consequência, faz referência ao romance narrativo, e assim cumpre uma função coesiva referencial.

\section{PROPOSTA DIDÁTICO-PEDAGÓGICA A PARTIR DA ANÁLISE DE UM TEXTO PREFACIAL}

Muito se ouve falar da dificuldade para trabalhar práticas de leitura em salas de aula de turmas do Ensino Básico. Muito provavelmente, isso deve ocorrer em virtude da desproporcionalidade entre a carga horária dos tempos de aula e a real necessidade de tempo que uma boa prática de leitura exige de quem pretende dedicar-se ao mundo dos livros. Sejam eles de qualquer especialidade ou gênero textual, livros sempre hão de demandar tempo para que possa efetivamente haver qualidade durante o processo de sua leitura.

Sendo assim, utilizar o tempo de aula para apresentar o livro como proposta de leitura poderia ser assunto e conteúdo de aula. Talvez esse procedimento, já a partir dos anos finais do Ensino Fundamental, venha ser uma possibilidade para despertar o interesse pela leitura de livros em estudantes pouco familiarizados com essa prática.

Diante da verdadeira impossibilidade de aumento da carga horária, por que, então, não começar essa jornada da prática de leitura em salas de aula explicando um pouco sobre cada um dos elementos que compõem o projeto gráfico de um livro? 
Talvez seja importante considerar que grande parte dos estudantes não tem conhecimento sobre o leiaute gráfico de um livro, ou mesmo quanto à funcionalidade de cada uma de suas partes, e que esse tipo de abordagem talvez tenha algum tipo de eficácia para a formação desses estudantes a fim de que, ao tomarem conhecimento do todo, deixem de julgar o conteúdo de um livro apenas pela capa.

Em seu estudo Leitura na escola: como estimular os alunos a ler, Leonor Werneck dos Santos (2011), ao discutir sobre leitura, sugere algumas atividades a partir do uso de textos literários e não literários em salas de aula, a fim de auxiliar no processo de formação de profissionais da educação. Nas palavras da autora, a formação do leitor crítico "deveria ser a principal tarefa da escola" (SANTOS, 2011, p. 64).

Apesar de haver quem defenda o compartilhamento dessa função entre todas as áreas de ensino, a tarefa de motivar estudantes a aprenderem a ler criticamente, ao que tudo indica demanda mais que vontade de fazê-la, é preciso planejamento e tempo para o desenvolvimento de atividades que proporcionem a prática de leitura com fins a formar estudantes que, de fato, sejam capazes de efetivamente ler de modo crítico, o que corresponderia a uma predisposição durante o ato de leitura, em "valorizar a construção do texto e a participação ativa do aluno no processo" (Ibidem, p. 66) de construção de sentido daquilo que se lê.

Levando-se em consideração que o processo natural de leitura parte daquilo que está explícito, ou seja, do uso vocabular em si, com sua significação básica, aquela dicionarizada que passa a compor a estruturação sintática de um enunciado qualquer, como introduzir o trabalho que leve em conta aquelas construções textuais repletas de elaborações ornamentadas pelo uso de tropos ou figuras de linguagem tão comuns em algumas interações sociocomunicativas?

Como prática didática, Santos (2011) também propõe a análise e o conhecimento de alguns componentes que compõem o livro como uma das atividades de sala de aula, segundo ela, essa seria uma das etapas do processo de leitura. Isso é o que ela coloca como etapa pré-textual ou de motivação. A autora também sugere, a partir de Koch e Elias (apud Santos, 2011, p. 68), que é preciso uma interação entre texto-leitor na construção do sentido.

Diante disso, após uma primeira leitura do texto prefacial em sala de aula, seria interessante começar a indagação pelo termo úrsula presente no fragmento "deixai, pois, 
que a minha ÚRSULA, tímida e acanhada, sem dotes na natureza, nem enfeites e louçanias de arte, caminhe entre vós" (REIS, 2018, p. 48), conforme passo a passo desenvolvido e já apresentado anteriormente no primeiro tópico. Em seguida, e após as respostas elaboradas pelas próprias crianças, um segundo passo seria, a partir do uso de recursos tecnológicos, sugerir que fosse feita uma busca desse termo na internet para que, posteriormente, fossem discutidas em sala não somente as respostas emitidas pelas crianças como as possíveis respostas obtidas pela busca em sites pré-selecionados e identificados por plataformas virtuais. Depois disso, e sob orientação, retornar ao texto escolhido como objeto motivacional de leitura, o prefácio, para então fazer uma releitura mais atenta às nuances composicionais, a fim de se alcançar a compreensão do termo úrsula, o que evidentemente faria com que fosse percebido o artifício de uso da linguagem tanto para a elaboração da significação no âmbito conotativo (referente à personagem protagonista da narrativa) quanto para a elaboração de um sentido que se aproxima de um significado denotativo o que leva para uma referenciação à leitura do próprio livro.

Já no que se refere ao estímulo à formação de leitores críticos, também colocada por Santos (2011), podem ser utilizadas as observações feitas nos trechos já analisados anteriormente, "com uma instrução misérrima, apenas conhecendo a língua de seus pais, e pouco lida" (REIS, 2018, p. 47) e "homens ilustrados, que aconselham, que discutem e que corrigem" (Ibidem, p. 47), extraídos do excerto abaixo que corresponde ao segundo parágrafo do prefácio.

não é a vaidade de adquirir nome que me cega, nem o amor-próprio de autor. Sei que pouco vale este romance, porque escrito por uma mulher, e mulher brasileira, de educação acanhada e sem o trato e a conversação dos homens ilustrados, que aconselham, que discutem e que corrigem, com uma instrução misérrima, apenas conhecendo a língua de seus pais, e pouco lida, o seu cabedal intelectual é quase nulo. (REIS, 2018, p. 47)

Conforme já mencionado, há nuances discursivas nesse fragmento que remetem às condições socioculturais da época e que podem ser entendidas como informações implícitas, mais especificamente, de acordo com Fiorin e Platão (2007), como pressupostos ou mesmo subentendidos.

No caso dos pressupostos, são "aquelas ideias não expressas de maneira explícita, mas que o leitor pode perceber a partir de certas palavras ou expressões 
contidas na frase" (FIORIN; PLATÃO, 2007, p. 241), o que de certa forma precisa ser admitido como verdadeiro entre os interlocutores para que haja efeito de sentido. Nesse caso, no referido trecho "a conversação dos homens ilustrados, que aconselham, que discutem e que corrigem" é possível identificar uma sequência de orações subordinadas atribuindo características ao sintagma nominal a conversação dos homens ilustrados. Orações essas que ao cumprirem a função de adjetivo no enunciado, explicitamente avaliam a condição daqueles que eram tidos como os homens ilustres do campo literário e implicitamente remete à condição subalterna da mulher no ramo de divulgação literária, o que pode estar no âmbito do subentendido para efeito da enunciação quando comparada ao que está explicitado e qualificado como "homens ilustrados".

Dessa maneira, essas colocações podem ser um modo de abordagem da linguagem verbal utilizada como artifício e estímulo à leitura e à formação de leitoras e leitores mais críticos.

\section{CONSIDERAÇÕES FINAIS}

Este estudo procurou demonstrar uma das aplicações de uso da linguagem verbal que deu origem à elaboração de um texto cuja finalidade prefacial já está bem consolidada como elemento de projeto gráfico em diversas composições e gêneros textuais.

Considerando que há muitas pessoas que ao terem a sua prática leitora bem desenvolvida, também têm pleno conhecimento sobre a função de um prefácio na produção de um livro, o ponto de partida para a análise neste trabalho foi buscar detalhar o estilo da linguagem empregada para a elaboração do sentido figurado no texto prefacial selecionado, como uma estratégia para motivar e incentivar a prática de leitura em estudantes dos anos finais do Ensino Fundamental.

Diante disso, ficou constatado que no texto que apresenta o romance Úrsula, de Maria Firmina dos Reis, foi possível identificar alguns traços de uso da linguagem figurada que, apresentados como recursos estilísticos, contribuíram para a formação do sentido global do texto. Traços esses cujo detalhamento foi feito a partir de observações sobre algumas escolhas e estruturação de itens lexicais e gramaticais na construção do sentido evidenciado pelo uso da metáfora, um dos elementos participantes do arranjo de 
ornamentação estética sendo apresentado no prefácio como uma extensão dos mesmos recursos presentes no texto narrativo elaborado em vinte capítulos.

Dessa maneira, para efeito didático-pedagógico o gênero prefácio pode ser um meio textual utilizado como estratégia não somente para o estudo de alguns assuntos da língua materna, como também, no que se refere aos trabalhos com leituras paradidáticas, poderia ser utilizado para incentivar o interesse pela leitura de fruição junto a estudantes a partir do Ensino Fundamental, o que demandaria um novo olhar para a formação docente a fim de que essa seja uma carreira atuante na mediação e na boa formação de estudantes.

\section{Referências}

AZEREDO, José Carlos de. Gramática Houaiss da língua portuguesa. 4. ed. São Paulo: Publifolha. Instituto Houaiss, 2018.

Biblioteca Pública Benedito Leite. Acervo digital. Úrsula: romance original brasileiro Maria Firmina dos Reis. Disponível em: https://www.cultura.ma.gov.br/portal/bpbl/acervodigital. Acesso em: 02 ago. 2019.

CRESSOT, Marcel. O estilo e as suas técnicas. São Paulo: Edições Setenta, 1947.

Definição ou significado de Úrsula no dicionário Infopédia de nomes próprios (Antroponímia). Disponível em: https://www.infopedia.pt/dicionarios/antroponimia/\%c3\%9Arsula. Acesso em: 25 nov. 2020.

FIORIN, José Luiz; PLATÃO, Francisco (Francisco Platão Savioli). Para entender o texto: leitura e redação. São Paulo: Ática, 2007.

GENETTE, Gérard. Paratextos editoriais. (Seuils). Tradução de Álvaro Faleiros. Cotia, SP: Ateliê editorial, 2009.

GUIRAUD, Pierre. A estilística. São Paulo: Editora Mestre Jou, 1970.

LAPA, Manuel Rodrigues. Estilística da língua portuguesa. São Paulo: Martins Fontes, 1982.

MARTINS, Nilce Sant'Anna. Introdução à estilística: expressividade na língua portuguesa. 4. ed. São Paulo: Edusp, 2012.

REIS, Maria Firmina dos. Úrsula. São Paulo: Companhia das Letras, 2018. 
SANTOS, Leonor Werneck dos. Leitura na escola: como estimular os alunos a ler. In: TAVARES, Kátia Cristina do Amaral; BECHER-COSTA, Sílvia B. A.; FRANCO, Claudio de Paiva (Orgs.). Ensino de leitura: fundamentos, práticas e reflexões para professores da era digital. Rio de Janeiro: Faculdade de Letras UFRJ, 2011. Livro eletrônico disponível em: http://www.claudiofranco.com.br/textos/ebook_leitura.pdf. Acesso em 30 mar. 2021.

SOUZA, Antonia Pereira de. A prosa de ficção nos jornais do Maranhão oitocentista. 2017. 329f. Tese (Doutorado em Letras). Universidade Federal da Paraíba. João Pessoa. 2017.

Recebido em: 27/11/2020 Aceito em: 02/04/2021

\footnotetext{
${ }^{1}$ Conceito sobre elementos paratextuais tratados por Gérard Genette em Paratextos editoriais (2009).

${ }^{2}$ Cf. Antonia Pereira de Souza, em sua tese de doutoramento A prosa de ficção nos jornais do Maranhão oitocentista - (UFPB/2017), no anúncio feito pelo periódico Publicador Maranhense, em 1860, não havia menção à autoria do livro, divulgado apenas como "Úrsula, romance original por uma maranhense".
} 